\title{
Career and research outcomes of the physician-scientist training program at the University of Calgary: a retrospective cohort study
}

\author{
Jason T. Bau BHSc, Alexandra D. Frolkis BSc, Nabeela Nathoo BSc, Bryan G. Yipp MD MSc, \\ Morley D. Hollenberg MD DPhil, Paul L. Beck MD PhD
}

Abstract

Background: Physician-scientists are integral to medical research, with medical programs throughout Canada invested in training hybrid physician-scientists. Few data exist as to whether these programs are generating the diversity, gender equity and numbers of trainees essential for the future of medical research and teaching. We aimed to identify factors that contribute to research productivity, diversity and retention of individuals as physician-scientists.

Methods: We completed a retrospective cohort study, for the period 1973 to 2015, of the University of Calgary Leaders in Medicine Program in Calgary, Alberta. Participants were coregistered in graduate (master's or PhD) and medical degree programs. Primary outcomes included number of publications and the eventual career paths of graduates, with individuals characterized as physicians or physician-scientists on the basis of these metrics.

Results: Of the 307 individuals who were coregistered in or had completed a joint graduate and medical degree, 125 (40.7\%) were PhD students/graduates, and $182(59.3 \%)$ were master's trainees/graduates. While in the joint program, male PhD students consistently published more frequently than female PhD students. There was no significant difference in publication records between male and female master's students. Of the 172 individuals who were 5 years or more beyond graduation, 47 (27.3\%) were classified as physician-scientists; these individuals consisted of 28 (40.6\%) of the $69 \mathrm{PhD}$ graduates and 19 (18.4\%) of the 103 master's graduates.

Interpretation: Overall, our study shows that graduates receiving both clinical and research training, through master's or PhD programs, continue to be involved in research in their subsequent careers.

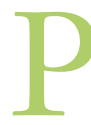
hysician-scientist programs are a core part of many medical training programs in North America. In the 1970s, MD/PhD programs were developed to address the dwindling number of research-trained physicians, individuals capable of speaking the "dual languages" of science and medicine. Apart from the US National Institutes of Health analysis of the outcomes of medical scientist training programs, ${ }^{1,2}$ few data exist for individual MD/PhD programs. This situation leads to several questions: Are these programs generating physicians actively involved in academic research, and might the structure of individual programs affect training outcomes for physician-scientists? Analyzing these outcomes is complicated by the fact that no universally accepted definition of a "physician-scientist" exists, nor are there optimal metrics for identifying successful outcomes. Furthermore, many physicians who are actively engaged in research, including those who have pursued master's programs or training within a postgraduate clinical residency environment, have not received formal training through an $\mathrm{MD} / \mathrm{PhD}$ program.
In traditional physician-scientist training programs, a small number of students are nurtured throughout the course of a structured MD/PhD program. Most of these programs provide mentorship and financial support, and encourage translational research initiatives. Generally, students in $\mathrm{MD} / \mathrm{PhD}$ programs complete their preclinical medical training before entering fulltime research and, upon completion of the research training, return to the clinical portion of the medical curriculum. Typically, 7 to 8 years are required to finish the academic program. Alternative designs exist for training physician-scientists. The University of Calgary has developed a unique training model ${ }^{3}$ whereby a large number students in both master's and doctoral programs are eligible for entry. Research programs outside the

Competing interests: None declared.

This article has been peer reviewed.

Correspondence to: Paul Beck, plbeck@ucalgary.ca

CMAJ Open 2017. DOI:10.9778/cmajo.20160103 
basic sciences are permitted, which has resulted in an expanded diversity of "unconventional" research areas, including philosophy, engineering and social sciences. Students may enter the physician-scientist pathway at multiple points during their training, which allows for flexibility in accommodating individual research programs. Unlike its sister programs in Canada, the joint program in Calgary does not have a set student quota, which has expanded the number of graduates receiving physician-scientist training. Given the dearth of data analyzing the outcomes of graduates from individual physician-scientist training programs, our aim was to examine the career and research outcomes of the Leaders in Medicine physicianscientist training program at the University of Calgary.

\section{Methods}

\section{Setting and data sources}

Using alumni data from the Cumming School of Medicine and the University of Calgary PRISM thesis database, we conducted a retrospective cohort study involving individuals who pursued joint graduate and medical studies at the University of Calgary from 1973 to 2015 . Individuals were eligible for inclusion if they were enrolled in or had completed a joint graduate and medical degree in the program. Student name, graduating degree and graduation year for all joint-degree students were identified using MD alumni data. PRISM, which indexes all graduate theses from the University of Calgary, was used to identify the sex of both the student and the graduate supervisor and the graduate degree department, and also to confirm the degree acquired and the year of graduation. When available, maiden names were incorporated into searches. Data were collected by 3 reviewers (JTB, ADF, $\mathrm{NN}$ ), with consensus reached on each participant.

Publication information for each student was identified using the National Institutes of Medicine PubMed and Web of Science databases. Publications were stratified as appearing before, during or after admission to the joint program. Level of authorship was extracted as first author, second author, senior author or any other level of authorship. The nature of the published study was categorized as original or review. Papers describing experimental work or epidemiologic systematic reviews were considered original, whereas literature reviews and commentaries were considered reviews.

\section{Identification of career paths}

Residency matching and current occupation were identified through the provincial colleges of physicians and surgeons and the Canadian College of Family Physicians. Current students were excluded from residency-related analyses. Current occupation was defined as student (those currently enrolled in the joint program), resident, fellow, physician or physicianscientist. Current students and those who graduated from the program less than 5 years previous were excluded from the physician-scientist analyses, to account for time to complete residency and fellowship programs. In addition to graduation from the joint program more than 5 years ago, physicianscientists were defined by the following criteria: a minimum total of 7 publications and 1 original publication in the past 5 years as either first or senior author. If any of these criteria were not met, the individual was classified as a physician. Sensitivity analyses were conducted to explore publication cutoffs ranging from a minimum of 4 up to 10 .

\section{Statistical analyses}

Publication record was analyzed as a continuous variable using Wilcoxon rank sum testing. Medians, interquartile ranges and means were calculated for each publication category, stratified by sex of the student and graduate degree. Post hoc sensitivity analyses were conducted in which 2 individuals with more than 100 publications were removed, as the data for these individuals could skew the publication estimates. Career path was analyzed as a categorical variable using Pearson $\chi^{2}$ tests, looking separately at residency and occupation (with a focus on physicians compared with physician-scientists).

Table 1: Participant characteristics

\begin{tabular}{|lc|}
\hline Characteristic & $\begin{array}{c}\text { No. (\%) of participants } \\
n=307\end{array}$ \\
\hline Sex & $165(53.7)$ \\
\hline Men & $142(46.3)$ \\
\hline Women & \\
\hline Career stage & $67(21.8)$ \\
\hline Current medical student & $240(78.2)$ \\
\hline Graduated & \\
\hline Graduate program & $93(30.3)$ \\
\hline Medical science & $55(17.9)$ \\
\hline Neuroscience & $24(7.8)$ \\
\hline Biological sciences & $17(5.5)$ \\
\hline Biochemistry & $15(4.9)$ \\
\hline Kinesiology & $14(4.6)$ \\
\hline Cardiovascular sciences & $13(4.2)$ \\
\hline Gastroenterology & $12(3.9)$ \\
\hline Immunology & $10(3.3)$ \\
\hline Microbiology & $5(1.6)$ \\
\hline Chemistry & $19(6.2)$ \\
\hline Community health sciences & $12(3.9)$ \\
\hline Engineering & $6(2.0)$ \\
\hline Philosophy & $6(2.0)$ \\
\hline Psychology & $4(1.3)$ \\
\hline Business & $2(0.6)$ \\
\hline Math & $182(59.3)$ \\
\hline Graduate degree* ${ }^{*}$ & \\
\hline Master's & \\
\hline PhD & \\
\hline${ }^{*}$ Earned or in progress. & \\
\hline
\end{tabular}


To identify the association between exposures of interest and career path, stepwise logistic regression was used, and odds ratios (ORs) and accompanying 95\% confidence intervals (CIs) were reported. For ease of interpretation, the number of publications for individuals in the joint program was stratified, after rounding up the mean number of publications for the purpose of this analysis, as fewer than 4 publications and 4 or more publications. Sensitivity analyses were conducted using 3 and 5 publications as cut-offs for stratification. Effect modification was explored by sex of student and degree obtained. Graduation year was explored as both a continuous variable and categorical exposure stratified in 5-year increments, with current students analyzed separately from graduates.

Statistical analyses were performed with an a priori $\alpha$ of 0.05 . Two-sided $p$ values were reported. All analyses were conducted using Stata 11.2, and figures were created using GraphPad Prism software, version 5.0.

\section{Ethics approval}

The Conjoint Health Research Ethics Board, Research Services, University of Calgary, waived the requirement for ethics approval because the study was retrospective and used data from publicly available sources.

\section{Results}

In total, 307 individuals completed the joint program from 1973 until 2015. Of these, the majority $(n=243[79.2 \%])$ were enrolled in science-based graduate programs (Table 1). Of the many graduate programs offered by the University of Calgary, students were most commonly enrolled in medical science $(n=$
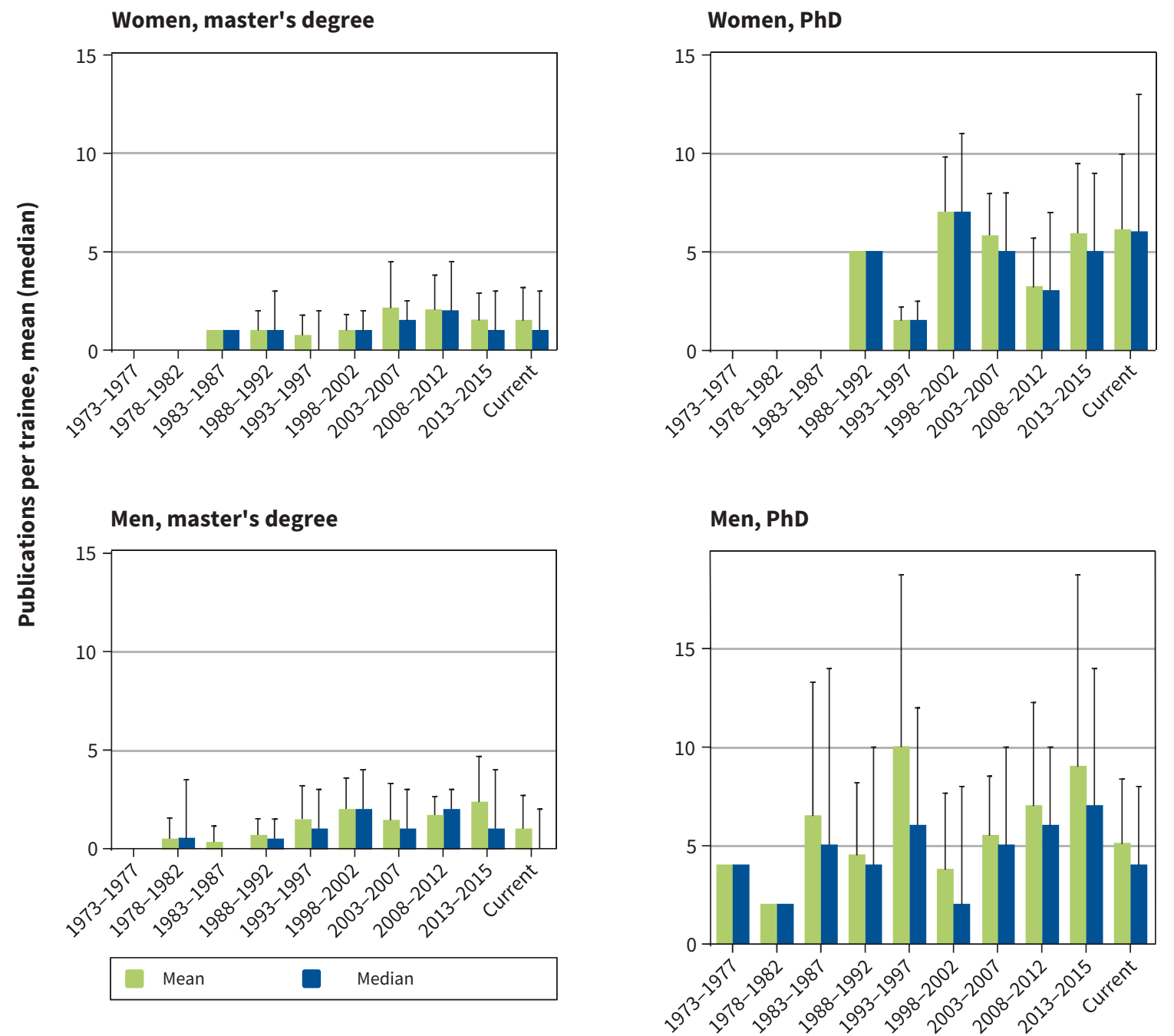

Figure 1: Means (with standard deviation) and medians (with interquartile range) of number of publications while in the joint program, stratified by degree and sex. Graduates were segregated by graduation period and graduate degree, and the mean number of publications per graduate was plotted. For bars where no standard deviation or interquartile range is shown, the sample size was very small $(n<3)$. 
$93[30.3 \%])$, neuroscience $(n=55[17.9 \%])$ and biological sciences $(n=24[7.8 \%])$. Those in nonscience programs constituted $20.8 \%(n=64)$ of the total joint-program population. Of the 182 master's students/graduates, 87 (47.8\%) were female, whereas 55 (44.0\%) of the $125 \mathrm{PhD}$ students/graduates were female.

\section{Research productivity}

Current and former PhD students consistently published more than current and former master's students (Figure 1). Among those who had graduated from the program, 17 (11.5\%) of the 148 master's students and $62(67.4 \%)$ of the $92 \mathrm{PhD}$ students published 4 or more times during their training period. There were no significant differences in number of publications between female and male master's students $(p=0.9)$ whereas male $\mathrm{PhD}$ students published more frequently than female $\mathrm{PhD}$ students. This difference was most significant for the median number of total publications including those published both during and after the joint program (median 5 [Q1, Q3: 2, 9] and mean 7.9 for women; median 9 [Q1, Q3: 4, 15] and mean 16.4 for men; $p=0.002$ ). Men also had higher numbers of first-author publications (median 2.5 [Q1, Q3: 1, 4] and mean 3.1 for women; median 3 [Q1, Q3: 2, 7] and mean 5.0 for men; $p=0.04$ ) and secondauthor publications (median 1 [Q1, Q3: 0, 2] and mean 1.2 for women; median 1 [Q1, Q3: 0, 4] and mean 2.6 for men; $p=$ 0.04). Among those who had graduated, men more often had 4 or more publications while in the joint program compared with women $(51 / 136$ [37.5\%] v. 28/104 [26.9\%], $p=0.08)$.

\section{Career path}

Of the 307 individuals, 67 (21.8\%) were current medical students and thus were excluded from the residency analyses. Of the 240 joint-program graduates across all programs, the largest proportion $(n=66,27.5 \%)$ matched to family medicine, followed by internal medicine $(n=55,22.9 \%)$. Female graduates, master's graduates and graduates with fewer than 4 publications while in the joint program significantly more often matched to family medicine than to other programs. The selection of residency programs was compared between physicians and physician-scientists (Figure 2). The most common residency program for physicians was family medicine, followed by internal medicine, pediatrics and anesthesiology. For physician-scientists, the most commonly selected residency program was internal medicine, followed by neurology and pediatrics.

The covariables that populated the final stepwise logistic regression model for family medicine were sex of the graduate and fewer than 4 publications. Female graduates had 2.07 times the odds of male graduates of matching to family medicine after adjustment for number of publications (OR 2.07, 95\% CI 1.15-3.73). Graduates with fewer than 4 publications had 2.64 times the odds of matching to family medicine relative to graduates with 4 or more publications after adjustment for sex (OR 2.64, 95\% CI 1.31-5.34). Effect modification was not identified. Neither sex of the graduate nor graduate degree nor publication record in the joint program was associated with matching to internal medicine.
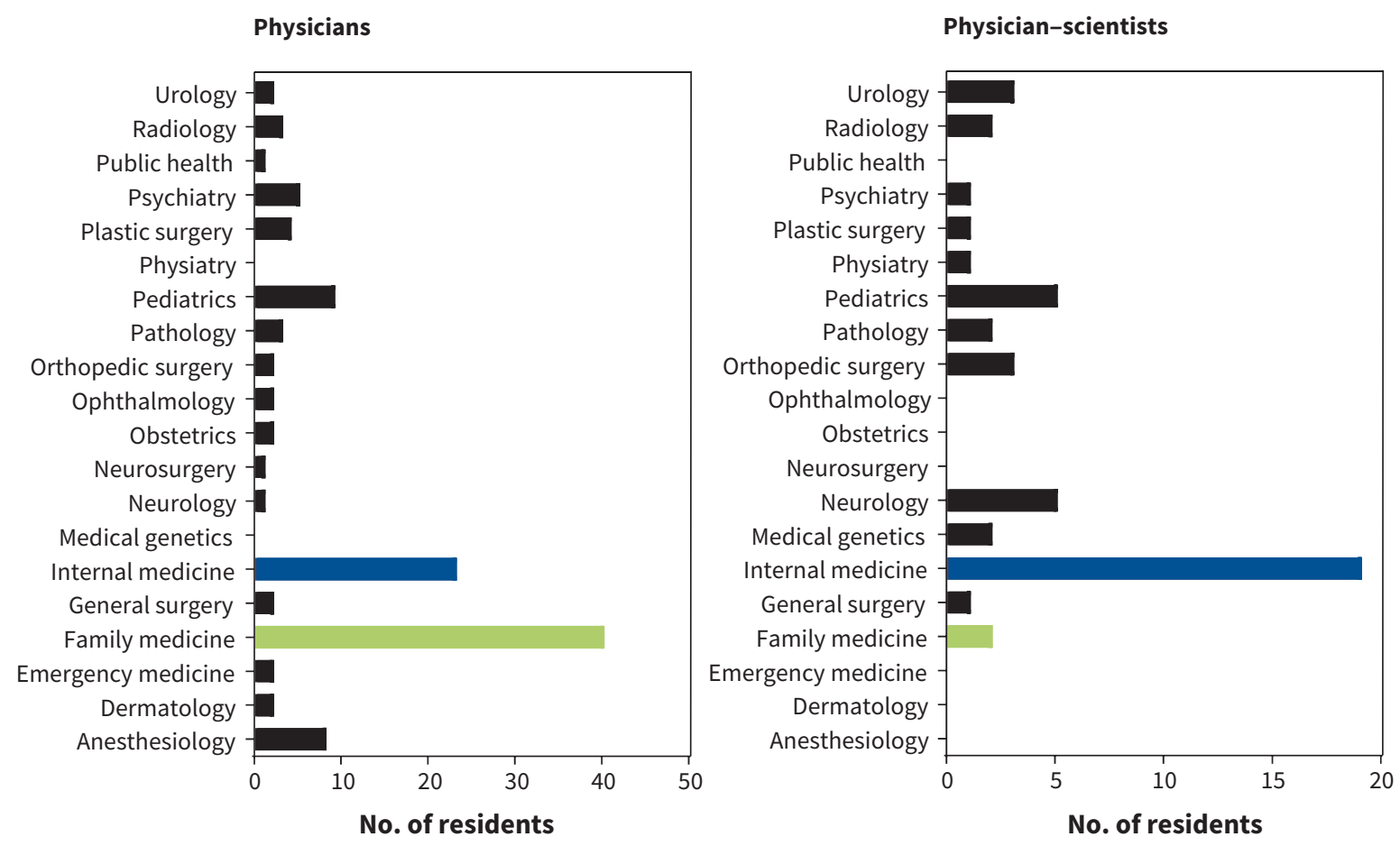

Figure 2: Residency distribution stratified by career path. Graduates were classified on the basis of their career category (physician v. physician-scientist) and plotted according to their entrance into a specific residency program. 
Of the 172 individuals across all graduate programs who were 5 or more years beyond graduation, $47(27.3 \%)$ were classified as physician-scientists, according to our definition (Table 2). Of the $69 \mathrm{PhD}$ graduates of the joint program, 28 (40.6\%) were classified as physician-scientists, compared with 19 (18.4\%) of the 103 master's graduates. Of the $28 \mathrm{PhD}$ graduates who were classified as physician-scientists, $6(21.4 \%)$ were female. In contrast, 8 (42.1\%) of the 19 master's graduates who were classified as physician-scientists were female (Table 3). Overall, graduates with 4 or more publications while in the joint program significantly more often were classified as physician-scientists than those with fewer than 4 publications. The only covariable to populate the final stepwise logistic regression model for who became a physician-scientist was having 4 or more publications while in the joint program. Those with 4 or more publications while in the joint program had 7.89 times the odds of classification as a physician-scientist relative to those who had fewer than 4 publications (OR 7.89, 95\% CI 3.66-16.99). After adjustment for sex, degree, graduation year, and 4 or fewer publications while in the joint program, family medicine residents had 0.12 times the odds of classification as a physician-scientist (OR $0.12,95 \%$ CI $0.02-$ $0.53)$, but the choice of internal medicine did not have a significant association with classification as a physician-scientist (OR $1.42,95 \%$ CI $0.27-7.43$ ). Effect modification was not identified by sex or degree. Author placement in article bylines by career path is available in Appendix 1, available at www.cmajopen.ca/ content/5/2/E395/suppl/DC1.

\section{Sensitivity analyses}

We performed sensitivity analyses exploring 3 and 5 publications as the cut-off for stratified analysis of research productivity while in the joint program. The cut-off choice did not change the observed trend (Appendix 2, available at www. cmajopen.ca/content/5/2/E395/suppl/DC1. Sensitivity analyses assessing publication cut-offs for the definition of physician-scientist were also completed, ranging from a minimum of 4 up to 10 publications. Similar trends were identified (Table 4). Specifically, regardless of the cut-off, more $\mathrm{PhD}$ graduates than master's graduates were classified as physician-scientists, and the sex distribution for master's graduates remained nearly even between men and women. Across all publication cut-offs, having 4 or more publications while in the joint program remained significantly associated with classification as a physician-scientist.

\section{Interpretation}

In our study, of 172 individuals who completed joint graduate and medical studies at a single institution and were at least 5 years beyond graduation, more than one-quarter continued research as

\section{Table 3: Characteristics of physician-scientists by graduating degree from joint program}

Graduating degree; no. $(\%)$ of physician-scientists

$\begin{array}{ccc}\text { Characteristic } & \mathrm{PhD} & \text { Master's } \\ & (n=28) & (n=19)\end{array}$

\section{Sex}

Male $22(78.6) \quad 11(57.9)$

Female $6(21.4) \quad 8(42.1)$

Residency

Family medicine $\quad 1(3.6) \quad 1(5.3)$

General surgery $\quad 0(0.0) \quad 1(5.3)$

Internal medicine $\quad 11(39.3) \quad 8(42.1)$

Medical genetics $\quad 1(3.6) \quad 1(5.3)$

Neurology $3(10.7) \quad 2(10.5)$

Orthopedic surgery $2(7.1) \quad 1(5.3)$

Pathology $1(3.6) \quad 1(5.3)$

Pediatrics $4(14.3) \quad 1(5.3)$

Physiatry $0(0.0) \quad 1(5.3)$

$\begin{array}{lll}\text { Plastic surgery } & 1(3.6) & 0(0.0)\end{array}$

Psychiatry $0(0.0) \quad 1(5.3)$

Radiology 1 (3.6) $1(5.3)$

Urology $3(10.7) \quad 0(0.0)$

Total publications in joint program

Mean $\pm S D$

$\begin{array}{lcc}\text { By men } & 6.6 \pm 7.0 & 1.9 \pm 1.9 \\ \text { By women } & 5.2 \pm 2.3 & 4.3 \pm 2.4 \\ \text { Median (Q1, Q3) } & & \\ \text { By men } & 5(3,8) & 2(0,4) \\ \text { By women } & 5(4,6) & 4.5(2,6)\end{array}$

Note: $\mathrm{Q} 1$ = first quartile, $\mathrm{Q} 3$ = third quartile, $\mathrm{SD}=$ standard deviation. *Except where indicated otherwise.

Table 2: Career outcomes of individuals more than 5 years beyond graduation, by sex and research training $(n=172)$

Subgroup; no. (\%) of participants

\begin{tabular}{|c|c|c|c|c|}
\hline \multirow[b]{3}{*}{ Career outcome } & \multicolumn{4}{|c|}{ Subgroup; no. (\%) of participants } \\
\hline & \multicolumn{2}{|c|}{ Men $(n=101)$} & \multicolumn{2}{|c|}{ Women $(n=71)$} \\
\hline & Master's $(n=55)$ & $\operatorname{PhD}(n=46)$ & Master's $(n=48)$ & $\operatorname{PhD}(n=23)$ \\
\hline Physician & $44(80.0)$ & $24(52.2)$ & $40(83.3)$ & 17 (73.9) \\
\hline Physician-scientist & $11(20.0)$ & $22(47.8)$ & $8(16.7)$ & $6(26.1)$ \\
\hline
\end{tabular}




\section{OPEN}

Research

Table 4: Sensitivity analyses exploring different publication cut-offs for definition of a physician-scientist

\begin{tabular}{|c|c|c|c|c|c|c|c|}
\hline \multirow[b]{2}{*}{ Characteristic } & \multicolumn{7}{|c|}{ Publication cut-off; no. (\%) of graduates* } \\
\hline & $\begin{array}{l}\geq 4 \text { publications } \\
\quad(n=52)\end{array}$ & $\begin{array}{l}\geq 5 \text { publications } \\
(n=51)\end{array}$ & $\begin{array}{l}\geq 6 \text { publications } \\
\quad(n=50)\end{array}$ & $\begin{array}{l}\geq 7 \text { publications } \\
\quad(n=47)\end{array}$ & $\begin{array}{c}\geq 8 \text { publications } \\
(n=45)\end{array}$ & $\begin{array}{c}\geq 9 \text { publications } \\
(n=44)\end{array}$ & $\begin{array}{c}\geq 10 \text { publications } \\
(n=43)\end{array}$ \\
\hline \multicolumn{8}{|l|}{ Total no.† } \\
\hline Male & $35(67.3)$ & $34(66.7)$ & $33(66.0)$ & $33(70.2)$ & $31(68.9)$ & $30(68.2)$ & $30(69.8)$ \\
\hline Female & $17(32.7)$ & $17(33.3)$ & $17(34.0)$ & $14(29.8)$ & $14(31.1)$ & $14(31.8)$ & $13(30.2)$ \\
\hline \multicolumn{8}{|c|}{ Master's students } \\
\hline Male & $13(54.2)$ & $12(52.2)$ & $11(50.0)$ & $11(57.9)$ & $10(55.6)$ & $9(52.9)$ & $9(56.3)$ \\
\hline Female & $11(45.8)$ & $11(47.8)$ & $11(50.0)$ & $8(42.1)$ & $8(44.4)$ & $8(47.1)$ & $7(43.8)$ \\
\hline \multicolumn{8}{|l|}{ PhD students } \\
\hline Male & $22(78.6)$ & $22(78.6)$ & $22(78.6)$ & $22(78.6)$ & $21(77.8)$ & $21(77.8)$ & $21(77.8)$ \\
\hline Female & $6(21.4)$ & $6(21.4)$ & $6(21.4)$ & $6(21.4)$ & $6(22.2)$ & $6(22.2)$ & $6(22.2)$ \\
\hline \multicolumn{8}{|c|}{ Residency choiceł } \\
\hline $\begin{array}{l}\text { Internal } \\
\text { medicine }\end{array}$ & $22(42.3)$ & $22(43.1)$ & $22(44.0)$ & $19(40.4)$ & $19(42.2)$ & $19(43.2)$ & $19(44.2)$ \\
\hline Neurology & $5(9.6)$ & $5(9.8)$ & $5(10.0)$ & $5(10.6)$ & $5(11.1)$ & $5(11.4)$ & $5(11.6)$ \\
\hline Pediatrics & $5(9.6)$ & $5(9.8)$ & $5(10.0)$ & $5(10.6)$ & $4(8.9)$ & $4(9.1)$ & $4(9.3)$ \\
\hline \multicolumn{8}{|c|}{ OR $(95 \% \mathrm{Cl})$ for classification as a physician-scientist§ } \\
\hline $\begin{array}{l}4 \text { publications } \\
\text { while in the } \\
\text { joint program }\end{array}$ & $\begin{array}{c}5.06 \\
(2.38-10.77)\end{array}$ & $\begin{array}{c}5.34 \\
(2.50-11.41)\end{array}$ & $\begin{array}{c}6.53 \\
(3.09-13.83)\end{array}$ & $\begin{array}{c}7.89 \\
(3.66-16.99)\end{array}$ & $\begin{array}{c}7.74 \\
(3.58-16.75)\end{array}$ & $\begin{array}{c}8.31 \\
(3.81-18.15)\end{array}$ & $\begin{array}{c}7.63 \\
(3.51-16.6)\end{array}$ \\
\hline \multicolumn{8}{|c|}{$\begin{array}{l}\text { Note: } \mathrm{Cl}=\text { confidence interval, } \mathrm{OR}=\text { odds ratio. } \\
\text { *Except where indicated otherwise. } \\
\text { †Total number of individuals classified as physician-scientists, according to the specified publication cut-off, of which one publication had the person as first or senior author } \\
\text { and was published in the last } 5 \text { years, with graduation from the joint program more than } 5 \text { years ago. } \\
\text { †Top } 3 \text { residency choices listed. } \\
\text { §Significant estimates from the stepwise logistic regression model that included sex of student, year of graduation, degree obtained (PhD v. master's), number of } \\
\text { publications while in the joint program (stratified as }<4 \text { and } \geq 4 \text { ) and residency choice (internal medicine v. other). }\end{array}$} \\
\hline
\end{tabular}

physician-scientists. Physician-scientists generally receive clinical training through more research-oriented specialties, predominantly internal medicine. Although the University of Calgary training model supports this trend, physician-scientists are present in an array of specialties, including family medicine and physiatry. ${ }^{4}$

In our study, the factor that best predicted future involvement as a physician-scientist was having 4 or more publications while in the joint program. Our findings corroborate those of a previous study showing that general surgeons who received physician-scientist training published significantly more often than general surgeons who did not receive combined training. ${ }^{5}$ In our data set, male students more often achieved the 4-publication milestone than female students, regardless of degree. Thus, there may be issues during the course of the joint program preventing female students from attaining the publication threshold predictive of becoming a physician-scientist. Differences in mentorship may be an area of discrepancy affecting women's publication levels in the joint program. Studies have shown that women are more prone to burnout than men during all stages of training, including as medical students, ${ }^{6}$ residents $^{7}$ and senior physicians. ${ }^{8}$
A cross-sectional study looking at graduates from $\mathrm{MD} / \mathrm{PhD}$ programs across the rest of Canada found that nearly $65 \%$ had coauthored 4 or more papers during their combined degree, 9 similar to the results we obtained for $\mathrm{MD} / \mathrm{PhD}$ graduates from our program (67.4\%). That study did not consider master's students, nor did it separate data by sex. Another cohort study, completed in the United States, found that the majority of $\mathrm{MD} / \mathrm{PhD}$ graduates became fulltime faculty members in academic medicine pursuing internal medicine, pathology, pediatrics or neurology. ${ }^{10}$ In that study, sex was not independently associated with the likelihood of a full-time faculty appointment. Those results were similar to our findings with respect to the specialties of graduates who were classified as physician-scientists (internal medicine, pediatrics, neurology).

Although $\mathrm{PhD}$ graduates who became physicianscientists were overwhelmingly male, the proportion of master's graduates who qualified as physician-scientists by our criteria was nearly evenly distributed between women and men. This remained true even after sensitivity analysis. Thus, investment in the training of $\mathrm{MD} /$ master's students not only increases the physician-scientist pool, but also leads to the training of more female physician-scientists. This 
outcome is particularly important as the sex divide among active physician-scientists has long been male-dominated. ${ }^{4,11}$ Reasons for this are multifactorial and difficult to isolate, but it is possible that length of training time might affect decisions to pursue further training.

\section{Limitations}

Our study had limitations. There is no consensus definition of a physician-scientist. We defined physician-scientists as graduates who had made clear contributions to research after graduation, according to their publication record, although we acknowledge that individuals who pursue a longer training program will theoretically have more opportunity to publish and fulfill the criteria of becoming a physician-scientist. However, even after exploring a range of publication records, the trends we identified support the same conclusions. Leading an independent research program as a principal investigator represents a key attribute of a physician-scientist, but this definition is too restrictive and does not account for individuals who contribute as collaborators. Our analyses did not include grant-funding data, as this information was incomplete and only partially publicly available. Many researchers have sources of funding apart from national granting agencies, so incorporating grant data only from publicly available sources (e.g., tri-council funding agencies), while excluding others (e.g., disease-specific grants from organizations) would not be a true reflection of a scientist's funding situation. We were unable to accurately evaluate and compare individual contributions to education, largely because of the many distinct ways in which such contributions could be defined. Contributions as an educator, particularly among graduates from the University of Calgary program, is a factor that we are continuing to examine.

\section{Conclusion}

Physician-scientists form an integral part of the medical community, and training these "bilingual" professionals is necessary to drive innovations in research and patient care. By incorporating both master's and $\mathrm{PhD}$ students in the training program, a greater number of active physician-scientists can be produced. Our findings suggest the need for strong mentorship for female students, who have been underrepresented in the past. Furthermore, encouraging master's-trained physicians may be a novel mechanism to deal with the discrepancy between male and female trainees. We hope that this innovative training approach will encourage graduates to remain active in clinical medicine and academic research while rectifying the worrisome trend of the decline of the physician-scientist.

\section{References}

1. McClellan DA, Talalay P. M.D.-Ph.D. training at the Johns Hopkins University School of Medicine, 1962-1991. FAMA 1992;67:36-41.

2. NIH Physician-Scientist Workforce Working Group report. Bethesda (MD): National Institutes of Health; 2014.

3. Miller D, Thornton CS, Keough MB, et al. A prescription that addresses the decline of basic science education in medical school. Clin Invest Med 2014;37:E284-91.

4. Andriole DA, Whelan AJ, Jeffe DB. Characteristics and career intentions of the emerging MD/PhD workforce. 7AMA 2008;300:1165-73.

5. Merani S, Switzer N, Kayssi A, et al. Research productivity of residents and surgeons with formal research training. 7 Surg Educ 2014;71:865-70.

6. Dyrbye LN, Thomas MR, Harper $W$, et al. The learning environment and medical student burnout: a multicentre study. Med Educ 2009;43:274-82.

7. Spataro BM, Tilstra SA, Rubio DM, et al. The toxicity of self-blame: sex differences in burnout and coping in internal medicine trainees. 7 Womens Health (Larchmt) 2016;25:1147-52.

8. McMurray JE, Linzer M, Konrad TR, et al. The work lives of women physicians results from the physician work life study. The SGIM Career Satisfaction Study Group. 7 Gen Intern Med 2000;15:372-80.

9. Skinnider MA, Squair JW, Twa DDW, et al. Characteristics and outcomes of Canadian MD/PhD program graduates: a cross-sectional study. CMAJ Open 2017;5:E308-14

10. Andriole DA, Jeffe DB. Predictors of full-time faculty appointment among MD-PhD program graduates: a national cohort study. Med Educ Online 2016;21:30941.

11. Andrews NC. The other physician-scientist problem: Where have all the young girls gone? Nat Med 2002;8:439-41.

Affiliation: Cumming School of Medicine, University of Calgary, Calgary, Alta.

Contributors: Jason Bau, Alexandra Frolkis and Nabeela Nathoo contributed equally as lead authors on this paper; they compiled the data and led the analysis. All of the authors contributed to conception and design of the project, to analysis and interpretation of the data, and to writing and revision of the manuscript for important intellectual content. All of the authors approved the final version for publication and agree to act as guarantors of the work.

Supplemental information: For reviewer comments and the original submission of this manuscript, please see www.cmajopen.ca/content $/ 5 / 2 /$ E395/suppl/DC1

Funding: Jason Bau is supported through a Canadian Institutes of Health Research MD/PhD Studentship. Alexandra Frolkis and Nabeela Nathoo are each supported through Alberta Innovates: Health Solutions $\mathrm{MD} / \mathrm{PhD}$ Studentships.

Acknowledgement: The authors wish to acknowledge Amy Waldman for presubmission editing assistance. 